\title{
Microbial Consortium Associated with the Antarctic Marine Ciliate Euplotes focardii: An Investigation from Genomic Sequences
}

\author{
Sandra Pucciarelli • Raghul Rajan Devaraj • \\ Alessio Mancini • Patrizia Ballarini • Michele Castelli • \\ Martina Schrallhammer • Giulio Petroni • Cristina Miceli
}

Received: 13 June 2014 / Accepted: 8 January 2015 / Published online: 24 February 2015

(C) The Author(s) 2015. This article is published with open access at Springerlink.com

\begin{abstract}
We report the characterization of the bacterial consortium associated to Euplotes focardii, a strictly psychrophilic marine ciliate that was maintained in laboratory cultures at $4{ }^{\circ} \mathrm{C}$ after its first isolation from Terra Nova Bay, in Antarctica. By Illumina genome analyser, we obtained 11,179 contigs of potential prokaryotic origin and classified them according to the NCBI's prokaryotic attributes table. The majority of these sequences correspond to either Bacteroidetes (16\%) or Proteobacteria $(78 \%)$. The latter were dominated by gamma- (39\%, including sequences related to the pathogenic genus Francisella), and alpha-proteobacterial (30\%) sequences. Analysis of the Pfam domain family and Gene Ontology term variation revealed that the most frequent terms that appear unique to this consortium correspond to proteins involved in "transmembrane transporter activity" and "oxidoreductase activity". Furthermore, we identified genes that encode for enzymes involved in the catabolism of complex substance for energy reserves. We also characterized members of the transposase and integrase superfamilies,
\end{abstract}

Sandra Pucciarelli and Raghul Rajan Devaraj contributed equally to this work.

Electronic supplementary material The online version of this article (doi:10.1007/s00248-015-0568-9) contains supplementary material, which is available to authorized users.

S. Pucciarelli $(\varangle) \cdot$ R. R. Devaraj $\cdot$ A. Mancini $\cdot$ P. Ballarini •

C. Miceli

School of Biosciences and Veterinary Medicine, University of Camerino, Camerino 62032, Italy

e-mail: sandra.pucciarelli@unicam.it

M. Castelli · G. Petroni

Department of Biology, University of Pisa, Pisa 56126, Italy

M. Schrallhammer

Institute of Biology II, University of Freiburg, Freiburg 79104, Germany whose role in bacterial evolution is well documented, as well as putative antifreeze proteins. Antibiotic treatments of E. focardii cultures delayed the cell division of the ciliate. To conclude, our results indicate that this consortium is largely represented by bacteria derived from the original Antarctic sample and may contribute to the survival of $E$. focardii in laboratory condition. Furthermore, our results suggest that these bacteria may have a more general role in E. focardii survival in its natural cold and oxidative environment.

Keyword Psychrophile $\cdot$ Proteobacteria $\cdot$ Bacteroidetes . Catabolism $\cdot$ Gene transfer $\cdot$ Antifreeze proteins

\section{Introduction}

The Antarctic polar region represents a natural laboratory for evolutionary ecology studies. The cold but thermally stable seawaters of the Southern Ocean offer a large source of microbial ecosystems useful for exploring speciation and evolution with limited phenomena of gene flow from outside biota. This is due to the geographical isolation of the Antarctic continent since its separation from Gondwanaland and the formation of the Polar Front 25 mya ago [1]. Ciliates (Ciliophora, Alveolata) represent a large fraction of eukaryotic microbes inhabiting the Antarctic coastal seawaters [2]. They are unicellular eukaryotes occupying ecological niches in nearly all environments, where they play an essential role in the "microbial loop" [3]. In challenging and harsh ecosystems, ciliates may host different bacterial species [4-6]. For instance, ciliates living in an anaerobic habitat recurrently harbor hydrogen-consuming-bacteria that can use hydrogen as their main and vital substrate $[7,8]$. Whether these bacteria have a key role in environmental adaptation and/or in enhancing the fitness of the host is not well established [7]. Even 
though some associations appear to be obligatory for both ciliates and bacteria, others may be ecologically advantageous but not vital for the host organism [9, 10].

Higher eukaryotic organisms including humans are intimately associated with complex communities of microbes, the so-called microbiome, which are essential for development, health, and interactions with the environment [11]. For example, the marine oligochaete Olavius algarvensis, a worm lacking mouth, gut, and nephridia, is associated with a microbial consortium that provides the host with multiple sources of nutrition and energy as it shuttles between the upper oxic and lower anoxic coastal sediments where it lives [12]. According to our best knowledge, bacterial consortia associated with ciliates have never been studied in detail. Among unicellular eukaryotes, such kind of studies have been performed in order to characterize the bacterial community associated to cultures of dinoflagellates and to determine their possible involvement of such consortia in the production of dinoflagellate toxins $[13,14]$. It has been shown that clonal cultures of Ostreopsis lenticularis show a peak of toxicity during the stationary growth phase, correlated with a significant increase in bacteria directly associated with these cells. This suggests a role in toxin production, at least in the laboratory culture [14].

Here, we report the characterization of the bacterial consortium associated to a laboratory culture of the marine ciliate Euplotes focardii [15]. This ciliate is a free-swimming protozoan endemic of the oligothrophic coastal sediments of Terra Nova Bay, in Antarctica. It has been maintained in the laboratory for more than 20 years after its first isolation. Its temperature optimum is about $4-5{ }^{\circ} \mathrm{C}$ with a decline at $8-10{ }^{\circ} \mathrm{C}$. $E$. focardii does not show a long survival if exposed to temperatures over $10^{\circ} \mathrm{C}[16,17]$. Therefore, it is classified as an obligate psychrophilic stenothermal organism [18-24]. By Illumina genome analyser, we obtained 11,179 contigs that were considered to be of prokaryotic origin. Most of these contigs matched with orthologous sequences from Proteobacteria and Bacteroidetes. The majority of the bacterial sequences were attributed to physiological adaptations to cold, oxidative environments and to facilitate horizontal gene transfer. The characterization of the bacterial consortium in E. focardii contributes to understand how different organisms cooperate for environmental adaptation.

\section{Materials and Methods}

\section{Cell Strains and Growth Conditions}

Cell cultures of the $E$. focardii strain TN1 and TN2 [15] were used. They were isolated from coastal sediment and seawater samples collected in Terra Nova Bay (Antarctica) at the beginning of 1988 and 1989 (Ross Sea: temperature, $-1.8^{\circ} \mathrm{C}$; salinity, 35\%; $\mathrm{pH}, 8.1-8.2)$. These cultures were grown at $4{ }^{\circ} \mathrm{C}$ and fed with the green alga Dunaliella tertiolecta.

DNA Isolation and Sequencing

DNA was purified from Euplotes focardii cultures as previously described [25]. Sequencing was performed by Illumina paired-end technology (a total of 43,588,788 reads covering 4, $402,467,588 \mathrm{bp}$, with an average read length of $100 \mathrm{bp}$ ), in collaboration with Dr. Vadim Gladishev's research group (Brigham and Women's Hospital and Harvard Medical School, Boston). The sequences were assembled using Newbler.

Preparation of Microbial Dataset and Data Analysis

To identify bacterial genomic sequences, all contigs were compared with bacterial genomes available from NCBI (ftp://ftp. ncbi.nlm.nih.gov/genomes/Bacteria/). For the identification of significant similarities, the e-value was set to 1e-1. Thus, identified sequences were subsequently compared with the nucleotide database of NCBI (ftp://ftp.ncbi.nlm.nih.gov/blast/db/). Obtained BLASTn results were uploaded in Linux version of MEGAN5 (Metagenome Analyzer) and binned [26]. Eukaryotic sequences identified after binning were removed from the dataset. The remaining sequences were considered to be potentially of bacterial origin and classified according to the NCBI's prokaryotic attributes table (derived from:http://www. ncbi.nlm.nih.gov/genomes/lproks.cgi). In total, the genome assembly of the bacterial consortium consisted of 11,179 contigs. The dataset was annotated and clustered using the CAMERA 2.0 (Community Cyberinfrastructure for Advanced Microbial Ecology Research \& Analysis) [27] workflow RAMMCAP (Rapid Analysis of Multiple metagenomes with a Clustering and Annotation Pipeline) for the identification of tRNA, rRNA, and ORFs. The ORFs were annotated against Pfam (release 26.0) [28], TIGRFAM 11.0 [29], and COG databases version 4.2.3. [30]. Hidden Markov model (HMM) based rRNA finding option was selected to identify rRNA genes [31]. Gene ontology and Pfam domain families comparison among the largely available groups was done using CoMet [32].

Phylogenetic Analysis

The 70 bacterial contigs containing (partial) 16S rDNA sequences were mostly non-overlapping and rather short, thus prohibiting a full phylogenetic analysis. Therefore, an alternative approach was applied. A set of almost full-length 16S rDNA reference sequences was selected from the NCBI nucleotide database, starting from the respective BLASTn results. One hundred twelve reference sequences were selected in this way and, together with the above mentioned contigs, aligned with more than 450,000 16S rDNA sequences (from the SILVA 111 
database release 2012 according to [33]) using the ARB software package 5.2 [34]. The aligned reference sequences were trimmed adjusting to the length of the shortest one at both ends. Moreover, due to the broad phylogenetic spectrum of reference sequences, more variable positions (i.e., columns comprising a single gap) were removed from the alignment. This final alignment comprised 1043 columns and was used to build the "scaffold tree" containing the selected 112 reference sequences. Phylogenetic reconstruction of the "scaffold tree" was performed using the maximum likelihood program PhyML [35] included in the ARB package [34]. The analysis was performed on the above mentioned final alignment applying the GTR $+\mathrm{I}+\mathrm{G}$ model. The selection of this model was confirmed by jModelTest2 (version 2.1.4) [36].

Subsequently, all except six short contigs were added to the "scaffold tree" with the Quick-add parsimony function of ARB, with the default ARB settings for bacterial sequences. For this purpose, considering that the reference sequences present in the "scaffold tree" were selected because of their high similarities to the newly characterized contigs, all nucleotide positions of the alignment, including highly variable ones, were used. Only $16 \mathrm{~S}$ rDNA-flanking regions, if present in the contig, were removed prior to the analysis.

\section{Identification of Francisella Homologues}

All available genome sequences of Francisella species were retrieved from NCBI site, and blast was performed with the microbial dataset. Reciprocal blast was done, and all the blast hits were collected. BLASTn and BLASTx were performed on NCBI database using default parameters to remove false positives and for sequence annotation.

\section{Antifreeze Protein Prediction}

Antifreeze protein prediction was done by AFP-Pred [37] and iAFP [38].

Antibiotic Treatments and Growth Rate Estimation of $E$. focardii Cells

To determine the suitable antibiotic concentration to remove the bacterial consortium associated to the ciliate, E. focardii cells were treated for 7 days with $1000 \mathrm{U} / \mathrm{ml}(1 \mathrm{U}$ equivalent to $0.6 \mu \mathrm{g}$ penicillin-G) of penicillin-G, and $1000 \mathrm{U} / \mathrm{ml}$ of streptomycin, or both, in sea water (salinity $33 \%$ ). The treated E. focardii cells showed normal capacity of dividing and moving. A control for each test was conducted with $E$. focardii cells not treated with antibiotics.

For the growth rate estimation of bacteria-free E. focardii cells, ten cells were collected from mass cultures, transferred into a 30-mm diameter Petri dish (Sterilin), fed with Dunaliella tertiolecta, and treated with both penicillin-G $(1000 \mathrm{U} / \mathrm{ml})$ and streptomycin (1000 U/ml). After 15 days, cells were transferred to the normal antibiotic-free culture medium and again fed with D. tertiolecta. The same number of cells was taken as control, fed in the same way, and maintained in an antibiotic-free medium. The number of cells was counted every $24 \mathrm{~h}$ for 20 day from the beginning of the experiment. Data and statistical analyses were performed using Excel.

\section{Results}

Characterization of the Microbial Diversity Present in the Consortium

By Illumina genome analyser, we obtained 11,179 contigs lacking at their ends the $5^{\prime}$-CCCCAAAA-3'/3'-GGGGTTTT-5' telomeric repeats characteristic of the Euplotes nanochromosomes. These contigs ranged in size from 100 to $25,584 \mathrm{bp}$ and did not correspond to any eukaryotic sequences after binning. Therefore, these contigs were considered to be of potential prokaryotic origin (termed here microbial dataset). Comparison to NCBI's prokaryotic attributes table showed that about 2600 of the entries were attributed to the categories "marine environment" and "Gram-negative bacteria" (Fig. 1). More than 2100 entries were associated to "motile bacteria", and nearly 600 entries were attributed to "psychrophilic microorganisms". Proteobacteria (78 \%) was the most abundant phylum of bacteria, represented mainly by Gammaproteobacteria (39\% of the total bacteria), followed by Alphaproteobacteria (30\%), and Betaproteobacteria (8\%) classes (Fig. 2a). Other sequences were classified as follows: Bacteroidetes (16\%) Firmicutes (2.64\%), Actinobacteria (1.22\%), Cyanobacteria (1.00\%), Chlamydiael Verrucomicrobia $(0.37 \%)$, Planctomycetes $(0.22 \%)$, Spirochaetes $(0.19 \%)$, Acidobacteria $(0.13 \%)$, and Fusobacteria $(0.09 \%)$, whereas $0.45 \%$ of the contigs affiliated to sequences from Archaea (due to the low number of Archea sequences the consortium will be referred as bacterial consortium). A similar distribution of the most represented classes was obtained by analyzing the 70 contigs corresponding to partial sequences of the 16S rDNA gene (Fig. 2b).

Phylogenetic Analysis of the Bacterial Consortium

Figure 3 shows the phylogenetic tree based on the 16S rDNA sequences selected from the NCBI nucleotide database with the added consortium contigs. At the higher taxonomic levels, the tree reflected almost perfectly the results of the BLASTn analysis. Additionally, in most cases, it was possible to recognize the affiliation of the contigs to the family or even genus rank. Several contigs cluster with bacterial sequences derived from habitats which share similarities to the Antarctic environment where the original sample of $E$. focardii was collected, such as the 


\section{Microbial attributes}

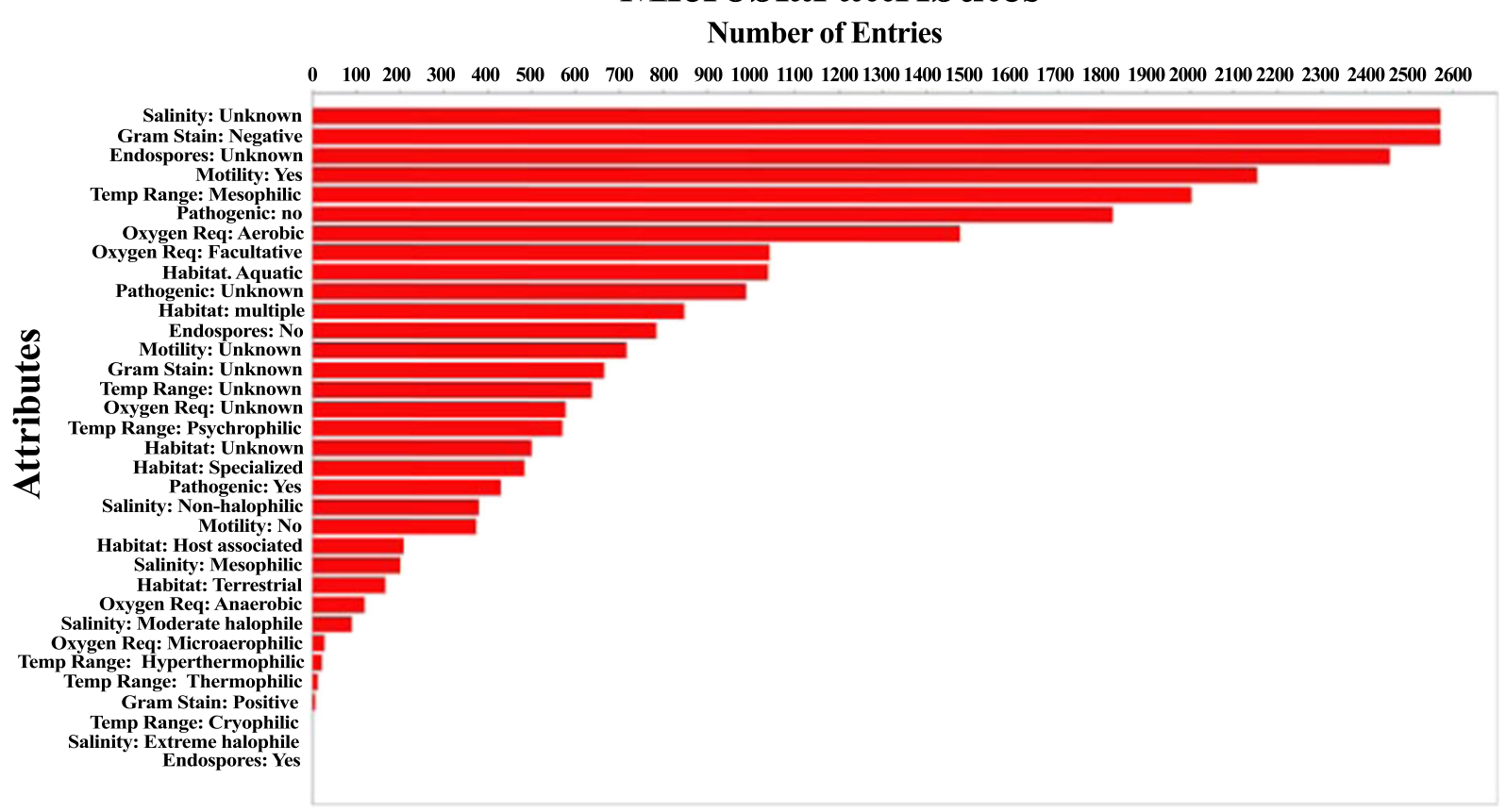

Fig. 1 Microbial attributes of the E. focardii bacterial consortium dataset

Alaskian Byron glacier [39], Arctic and Antarctic coastal seawaters, or other cold environments (e.g., Colwellia psychrerythraea, Ahrensia kielensis, Octadecabacter arcticus, etc.) [40-42]. Furthermore, we detected phylogenetic relationships to sequences retrieved from bacteria living in tight association with eukaryotic organisms (e.g., Arenibacter echinorum, originally isolated from the sea urchin Strongylocentrotus intermedius, and Porticoccus hydrocarbonoclasticus, found associated with the dinoflagellate Lingulodinium polyedrum $][43$, 44], and, notably, even to genera that encompass endosymbionts of ciliates (i.e., Francisella and Devosia) [10, 45]. We additionally observed that some contigs are affiliated with organisms characterized by special metabolic repertoires (e.g. Marinosulfonomonas methylotropha, Methylotenera mobilis or P. hydrocarbonoclasticus) $[43,46]$ or possess genomes rich in transposases and other mobile genetic elements (genus Octadecabacter) [47].

Characterization of Enzymes Involved in Recycling of Organic Matter and/or Biodegradation

The phylogenetic analysis showed that some members of the bacterial consortium of $E$. focardii are closely related to species involved in recycling organic material or in biodegradation. In fact, it is already documented that strains of Flavobacteria isolated from Antarctic marine waters have an important role in recycling organic material present in the sea floor [48]. Furthermore, Colwellia psychrerythraea is able to produce polyhydroxyalkanoate (PHA) compounds, a family of polyesters that serve as intracellular carbon and energy reserves, some of which have been linked to pressure adaptation [49]. To identify bacterial sequences of the Euplotes consortium potentially involved in these metabolisms, the microbial dataset was explored by tBLASTn using as query a selection of corresponding key enzymes (Table S1). The results (Table S2) revealed the presence of both polyhydroxyalkanoate synthase and depolymerase, suggesting that also the members of the E. focardii consortium are able to produce PHA compounds and use them as energy reserves. Contigs encoding enzymes involved in the degradation of aromatic compounds, as catechol 2,3 dioxygenase and naphthalene-degradation, were also detected. We also identified contigs encoding cyanophycin synthases (cyanophycin-like compounds serve as nitrogen reserves) (Table S2). Furthermore, members of these bacterial consortium possess enzymes that enable the utilization of aromatic compounds for growth, such as Anthranilate 1,2-dioxygenase, and of F420-dependent NADP reductase [50]. Coenzyme F420 was first found in methanogens where it is important in methanogenesis [51]. The bacterial organism Rhodococcus uses the coenzyme F420 for polynitroaromatic compound degradation. These results suggest that members of the bacterial consortium are able to carry out aromatic compound metabolism, an important ability for utilizing alternative carbon sources.

Gene Ontology Annotation of the Bacterial Contigs

Gene Ontology (GO) annotation was performed for contigs belonging to the three dominant taxa, i.e.,Gammaproteobacteria (g), Alphaproteobacteria (a), and Bacteroidetes (b) (Fig. 4). A gene description and GO classification based on the "best hit" 
Fig. 2 Pie charts of the taxonomic abundance of the bacterial consortium based on BLASTn results of all the contigs (a) and of the 16S rDNA sequences (b)

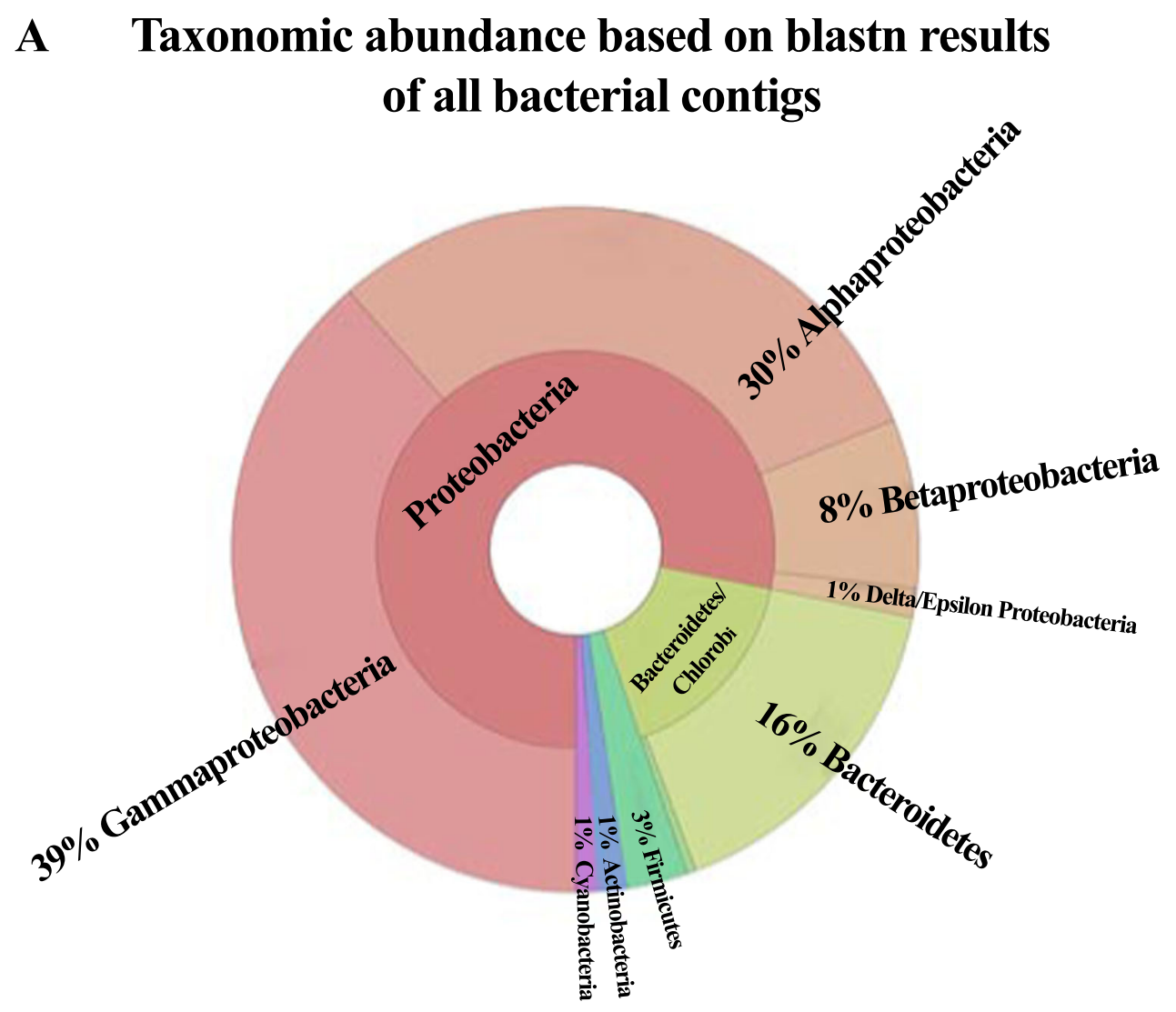

B Taxonomic abundance based on blastn results

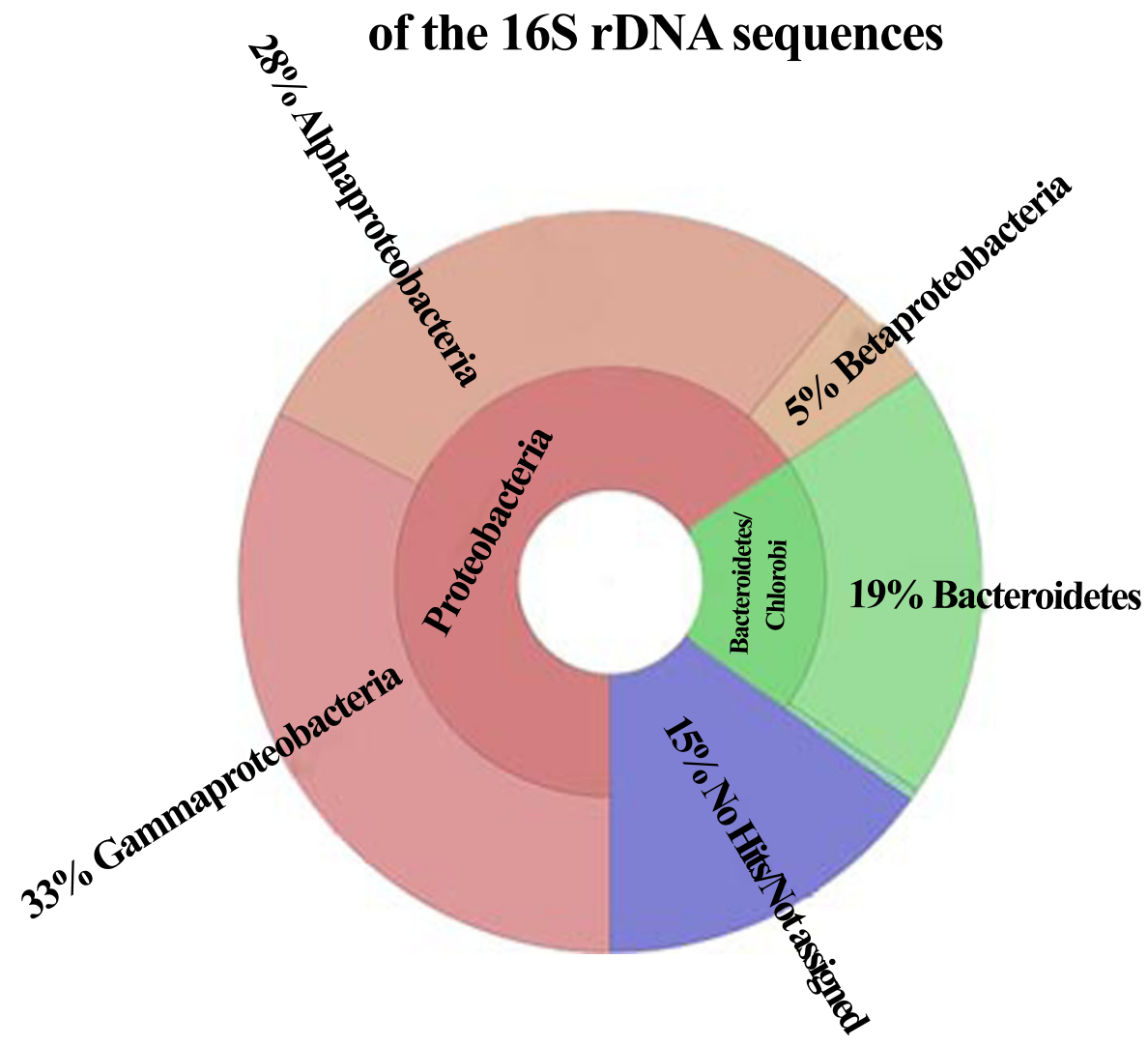




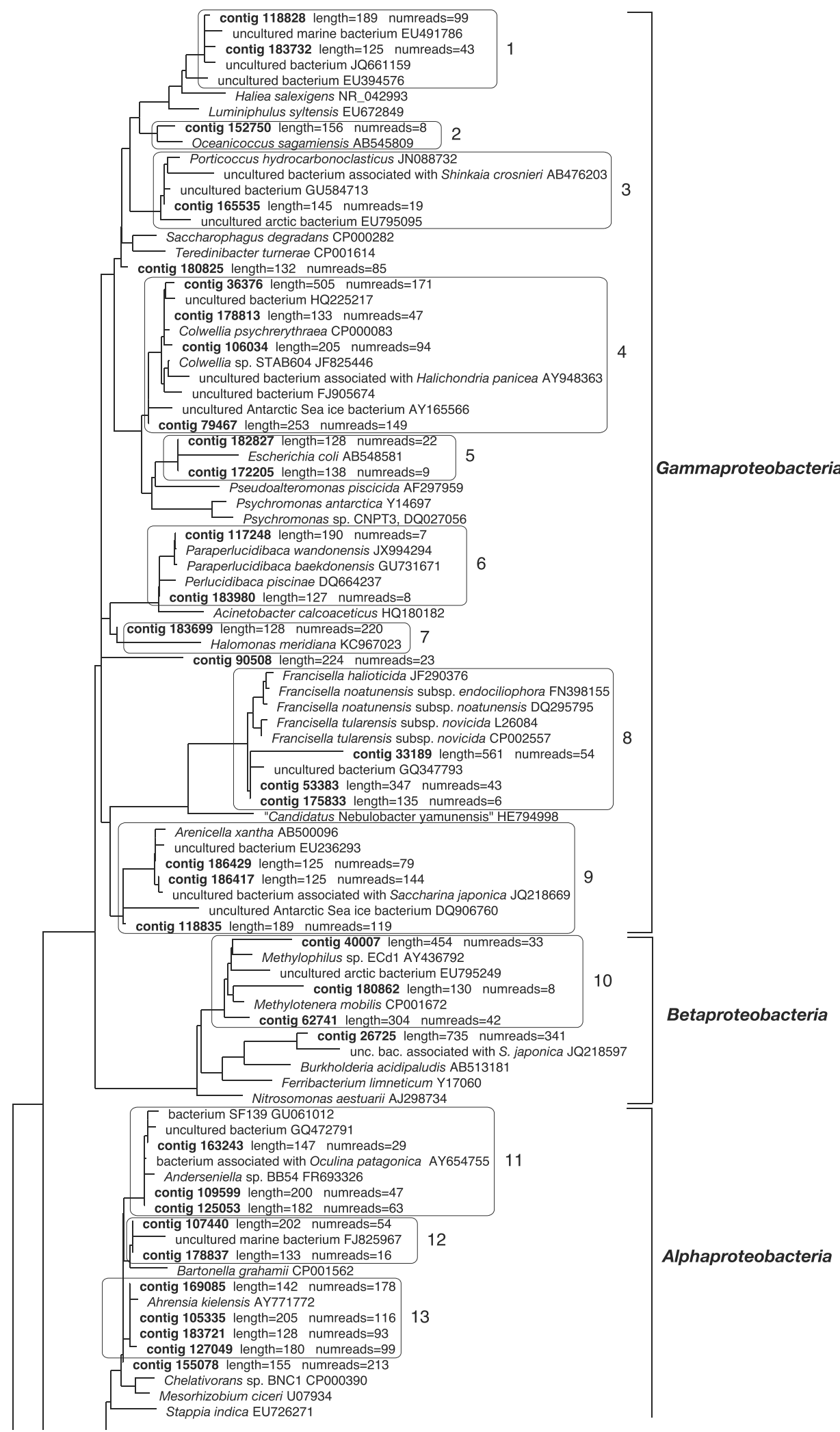

Fig. 3 Maximum likelihood phylogenetic tree based on 16S rDNA reference sequences (available in the ARB database) with the subsequent addition of 64 contigs of $16 \mathrm{~S}$ rDNA retrieved from the consortium (listed in Fig. S1. Due to graphic requirements, the branches between ingroup and outgroup are not shown entirely, the full tree is available in the Supplementary Material). Phylogenetically-related contigs have been enclosed, for clarity, in a box together with their closest relatives. A total of 23 such groups were identified, nine among Gammaproteobacteria, one among Betaproteobacteria, six among Alphaproteobacteria, one among Verrucomicrobia, five among Bacteroidetes, and one among Planctomycetes 


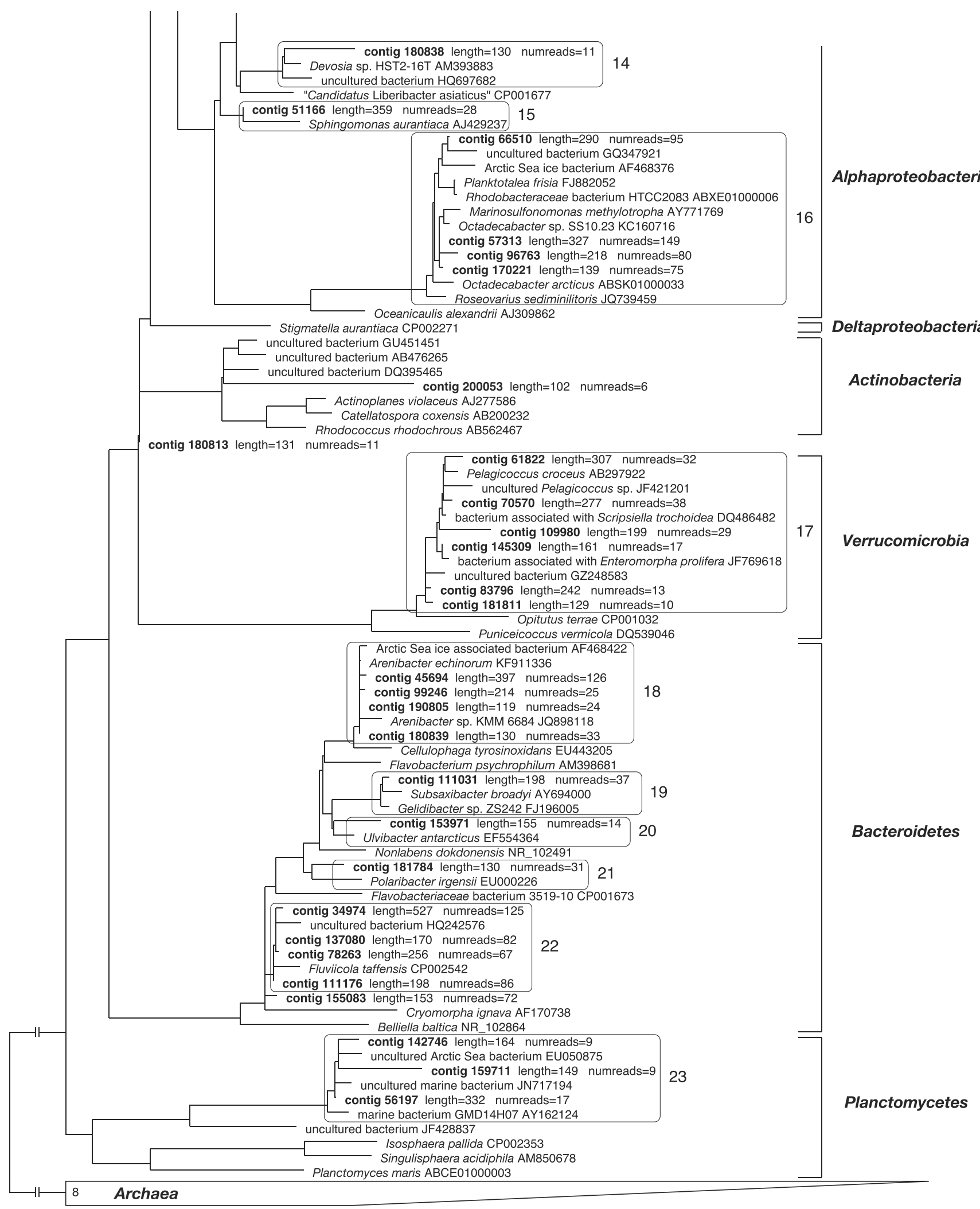

Fig. 3 (continued)

from the blastx search was assigned to each contig. For simplicity, only the categories of the three bacterial groups whose rounded off values were $1 \%$ or higher were reported (Fig. 4). In the three groups, the most frequent Molecular Function 
Fig. 4 Gene Ontology (GO) annotation of the dataset from the three most represented bacterial groups (Gammaproteobacteria, Alphaproteobacteria, and Bacteroidetes) for molecular function (a) and biological processes (b). In each panel are reported rounded off percentages of the represented terms. In cases in which rounded off percentage values were identical for the three bacterial groups, only one value is reported in black (e.g., ion binding, $9 \%$ ); in cases in which rounded off percentage values were differing in the three group, the different values are reported in red and they, respectively, refer to Gammaproteobacteria (g), Alphaproteobacteria (a), and Bacteroidetes (b)
A Molecular function

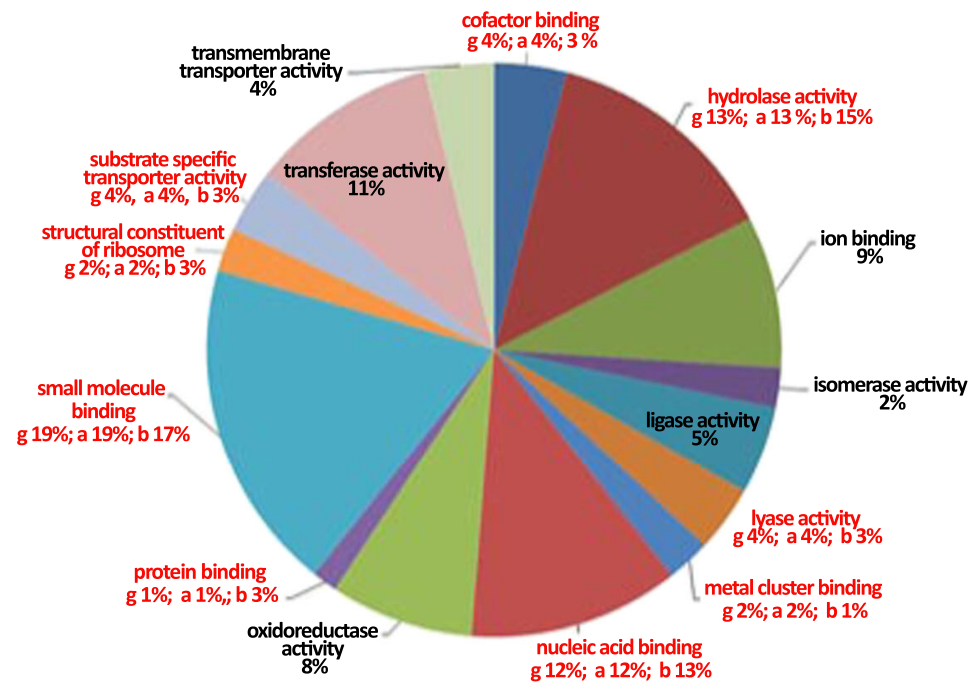

B

Biological processes

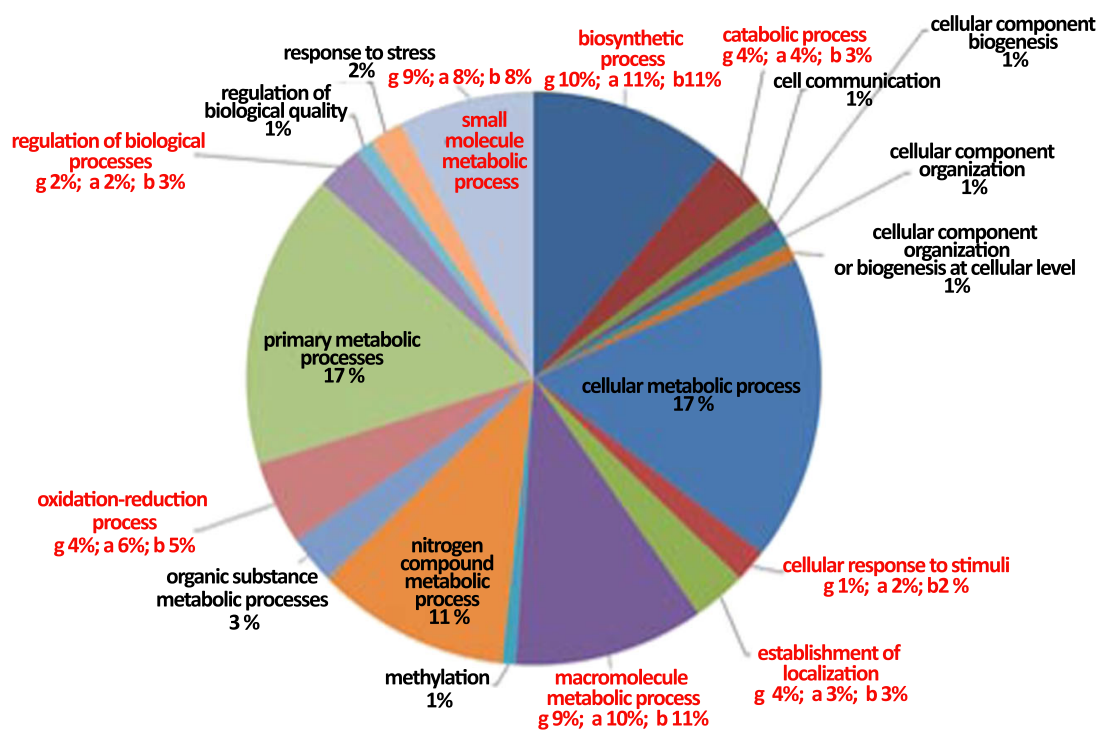

categories were "small molecule binding" (19\% (g), $19 \%$ (a), and $17 \%(\mathrm{~b})$, respectively), hydrolase activity (13\% (g), $13 \%$ (a), and $15 \%$ (b)), nucleic acid binding (12\% (g), $12 \%$ (a), $13 \%$ (b)), transferase activity (11\%), ion binding (9\%), and oxidoreductase activity $(8 \%)$. For the "Biological Process" categories, the largest number of contigs corresponded to molecules involved in cellular metabolic processes $(17 \%)$, primary metabolic processes $(17 \%)$, and nitrogen metabolism (11\%) (Fig. 4b).

Comparative Functional Profiling of Bacterial Contigs: Variation of Pfam and GO Terms

We also estimated the most represented functional categories in the three dominant bacterial groups (Gammaproteobacteria,
Alphaproteobacteria, and Bacteroidetes) in the consortium with respect to the metagenome dataset available in the CoMet server [32]. The bar charts in Fig. 5a, b show the Pfam domain frequencies and GO term categories, respectively, with the highest frequencies in the consortium ( $x$-axis values) and the largest terms variation compared to precomputed profiles obtained from microbial metagenomes in the CoMet server ( $y$-axis values). This comparison is crucial for an understanding of community specific properties that are possibly linked with particular environmental factors. From this analysis, it resulted that the Pfam domain family with the largest variation with respect to the other microbial metagenomes is represented by proteins involved in transmembrane transport (Fig. 5a). The GO-terms analysis shows proteins involved in "oxidoreductase activity" at the highest value of variation, thus suggesting a high metabolic 


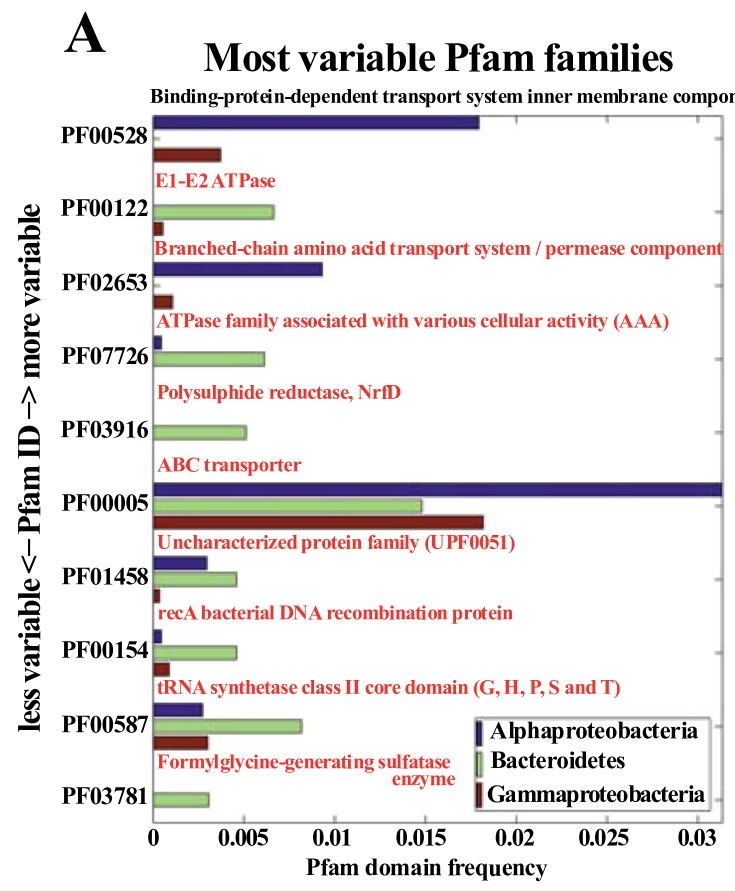

Fig. 5 Variable Pfam families and GO terms among the three most represented bacterial groups (Gammaproteobacteria, Alphaproteobacteria, and Bacteroidetes) done using CoMet [32]. The bar charts show the Pfam domain (a) and GO term categories (b) with the highest frequencies in the

potential of the consortium to survive in an oxygen-rich environment, followed by the "catalytic activity" and "molecular function" terms (Fig. 5b).

Identification of Sequences Encoding Ice-Binding Proteins

We focused on bacterial sequences encoding ice-binding proteins (IBPs) or antifreeze (AFPs) as these are considered the evolutionary key molecules for cold-adaptation. We found two sequences organized in tandem in the same contig: one is $57.43 \%$ identical to the antifreeze protein from the Stigmatella aurantiaca strain DW4/3-1, which was isolated from the glacier of the Lower Victoria valley (Antarctica) [52] and the second is $52 \%$ identical to the IBP from the Flavobacteriaceae bacterium strain 3519-10, which was isolated from the glacial ice of the Lake Vostok [53]. These two sequences have been previously described in detail in [54]. Furthermore, the complete genomic dataset was explored by performing a tBLASTn using AFP sequences from the diatom Fragilariopsis cylindrus as queries. We found four contigs (Table S3) that are similar to the bacterial type I AFP from Rhodobacteraceae bacterium HTCC2083 [55] and one sequence sharing $45 \%$ similarity to type II AFP from the catadromous fish Lates calcarifer [56]. Finally, we performed a prediction of putative AFP using AFP-Pred and iAFP bioinformatic tool as described above. Following this approach, we found 2755 or 600 (using AFP-Pred respectively iAFP) contigs that potentially encode AFPs in Gammaproteobacteria, 2251 or 500 (by AFP-Pred respectively iAFP) in

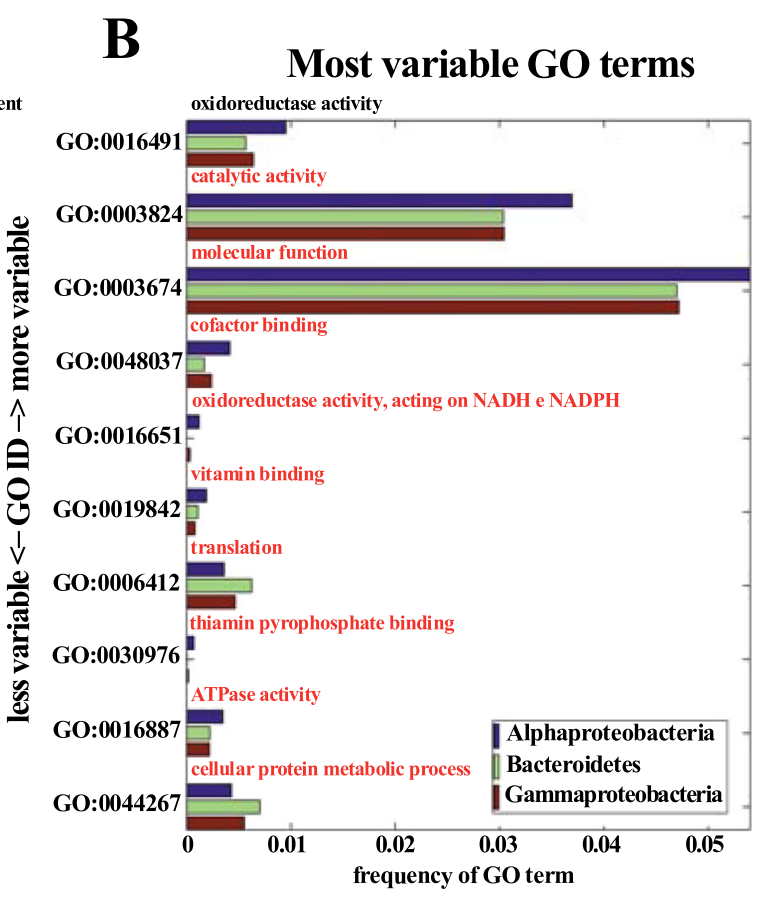

consortium ( $x$-axis values), and the largest terms variation with respect to precomputed profiles obtained from microbial metagenomes in the CoMet server ( $y$-axis values)

Alphaproteobacteria, and 942 or 200 (by AFP-Pred respectively iAFP) in Betaproteobacteria. These sequences may represent new AFPs whose AFP activity waits for verification.

Identification of Sequences Involved in Horizontal Gene Transfer

Gene transfer between cells is a powerful mechanism of genome evolution [57]. One interesting mode of gene transfer is carried out by gene transfer agents (GTAs), phage-like elements that package small segments of the genome of a GTA-producing cell and transmit these genes throughout the environment [57]. These genes have been characterized principally in Alphaproteobacteria [57].

In the $E$. focardii bacterial consortium, we identified a putative GTA encoding gene with a similarity of $89 \%$ to a putative GTA protein from the Alphaproteobacterium Ahrensia kielensis [58]. Furthermore, we also found contigs that correspond to members of the transposase and integrase superfamilies (see Table S4). Transposable genetic elements (TEs) and transposition may play a profoundly generative role in genome evolution and adaptation (see Discussion).

Identification of Francisella Sequences

In addition to $16 \mathrm{~S}$ rDNA sequences, we identified further 193 contigs $(1.70 \%$ of all non-16S rDNA containing bacterial contigs) that showed a high similarity to sequences from 
representatives of the genus Francisella [59]. These species are: $F$. cantonensis (1 contig), F. novicida (40 contigs), F. tularensis (42 contigs), F. noatunensis (30 contigs), F. philomiragia (41 contigs), Francisella sp. GP-2009 (2 contigs), and Francisella sp.TX077308 (37 contigs) (see table S5). Twenty-two contigs correspond to 23S rDNAs or ribosomal proteins. By gene annotation, the following categories were identified: stress response, transport, protective mechanisms against viruses, enzymes involved in substrate degradation, catabolism and metabolism, DNA mobilization and repair, and cell cycle (see Table S5). We also identified a transposase and DNA mismatch repair enzyme with ATPase activity showing high similarity to that of the human pathogen F. tularensis [60].

\section{Contribution of the Bacterial Consortium to E. focardii} Growth Under Laboratory Conditions

In order to test the possible contribution of the bacterial consortium to $E$. focardii cold-adaptation, the viability and proliferation of $E$. focardii cells under laboratory conditions after treatment of the cultures with the antibiotics penicillin and/or streptomycin was analyzed. The genomic DNA from E. focardii cells was extracted after the antibiotic treatment, and PCR was performed using a mix of oligonucleotides amplifying a conserved fragment of the $16 \mathrm{~S}$ rDNA sequence (170 bp). No PCR product was obtained in the sample from E. focardii cells treated with both antibiotics (Fig. 6a), confirming that only the treatment with both penicillin-G and streptomycin efficiently remove the bacterial consortium from $E$. focardii cultures. Subsequently, we analysed the growth rate of $E$. focardii cells after the combined treatment with the two mentioned antibiotics over a period of 20 days. $E$. focardii cells showed a significant lower growth rate ( $p$ val$\mathrm{ue}=0.0224$ ) with respect to the control (i.e., not previously treated with the two antibiotics; Fig. 6b). This result suggests that the bacterial consortium is not essential for the survival of $E$. focardii cells, but its elimination reduces cell proliferation capabilities.

\section{Discussion}

In this study, we report the characterization of the bacterial consortium associated to a long-term stabilized culture of the psychrophilic ciliate $E$. focardii, a species endemic of the Antarctic coastal seawaters [15]. To our best knowledge, this is the first bacterial consortium associated to a stabilized ciliate culture that has been characterized so far. Indeed, in the last years, several studies on ciliate-bacteria associations focused on the characterization of bacterial symbionts of ciliates [6, 61-64], but in no cases, a detailed analysis of the microbial consortium associated to cultured cells were performed. In the present study, a metagenome-like approach followed by a bioinformatic analysis allowed to characterize the bacterial community presently associated to an $E$. focardii strain culture maintained in laboratory for more than 20 years. Unlike the signature genes approach, that in most of the cases is based on the analysis of the $16 \mathrm{~S}$ ribosomal RNA genes, this metagenomic approach allowed us to obtain a much wider genetic information of the microbial community, and was used to generate also a description of the functional potential of the investigated bacterial consortium. This consortium may have an important role in defining the ecological potential of the ciliates in terms of growth capabilities and adaptation to cold environments. The binning of the bacterial dataset revealed that most of the contigs of this microbial consortium correspond to orthologous sequences from Proteobacteria (66\%) and Bacteroidetes (19\%). Intriguingly, the pattern of taxonomical distribution found in this long lasting E. focardii laboratory strain is similar to the one recently reported from an environmental metagenome from Alaskan glacier [38]. More than 600 of the characterized sequences showed psychrophilic features suggesting that a significant fraction of the bacterial community associated to $E$. focardii culture may still be representative of the original bacterial community derived from the original Antarctic sample. This possibility is also supported by phylogenetic analysis of retrieved $16 \mathrm{~S}$ rDNA sequences that, in many cases, showed to be related to bacterial strains or uncultured organisms derived from an Arctic or Antarctic environment. Escherichia coli related contigs in the phylogenetic tree may represent a low contamination either in the consortium or that occurred during sample preparation (e.g. DNA extraction, library construction, etc.), or may derive from representatives of Enterobacteriaceae actually present in the consortium, but not necessarily from $E$. coli. The $16 \mathrm{~S}$ rDNA is not commonly used as exclusive phylogenetic marker for the identification of $E$. coli or other members of the family Enterobacteriaceae because they all share rather high $16 \mathrm{~S}$ rDNA similarities. Generally, other genes such as gyrB and rpoA are used for taxonomy in combination with $16 \mathrm{~S}$ rDNA in this family.

The phylogenetic analysis also enables the identification of the bacterial genera that compose the consortium. Some of these contigs appear closely related to the strictly psychrophilic Gammaproteobacteria Colwellia psychrerythraea 34H strain, isolated from Antarctic sea sediments [41]. Other contigs appear closely related to representatives of the genus Francisella, which are facultative intracellular microbes causing severe disease in a broad range of animals. In particular, F. tularensis is the causative organism of tularemia and a putative warfare agent, whereas $F$. noatunensis is an emerging fish pathogen causing significant losses in wild and farmed fish [64]. Protists have been suspected to serve as a disguised vector of Francisella, and co-culturing attempts demonstrated that some species are able to survive and multiply within protozoan cells $[65,66]$. A representative of Francisella has been previously characterized as endosymbiont in another Euplotes species 
Fig. 6 Analysis of E. focardii cells previously exposed to antibiotic treatments. a Agarose gel of PCR reaction performed on purified genomic DNA from E. focardii cells without antibiotics (lane 1) and after treatment with $10^{3} \mathrm{U} / \mathrm{ml}$ of penicillin-G (lane 2), $10^{3} \mathrm{U} / \mathrm{ml}$ of streptomycin (lane 3 ), and with a mix containing $10^{3} \mathrm{U} / \mathrm{ml}$ of both penicillin-G and streptomycin (lane 4), using as primers a mix of oligonucleotides that amplify a fragment of $170 \mathrm{bp}$ of the $16 \mathrm{~S}$ rDNA sequences. b Growth rate of untreated E. focardii cells associated to their long lasting microbial consortium and E. focardii cells preliminary treated with a mix containing $10^{3}$ $\mathrm{U} / \mathrm{ml}$ of both penicillin- $\mathrm{G}$ and streptomycin for 15 days to deplete the microbial consortium associated to the ciliate. The cells were counted for 20 days
A
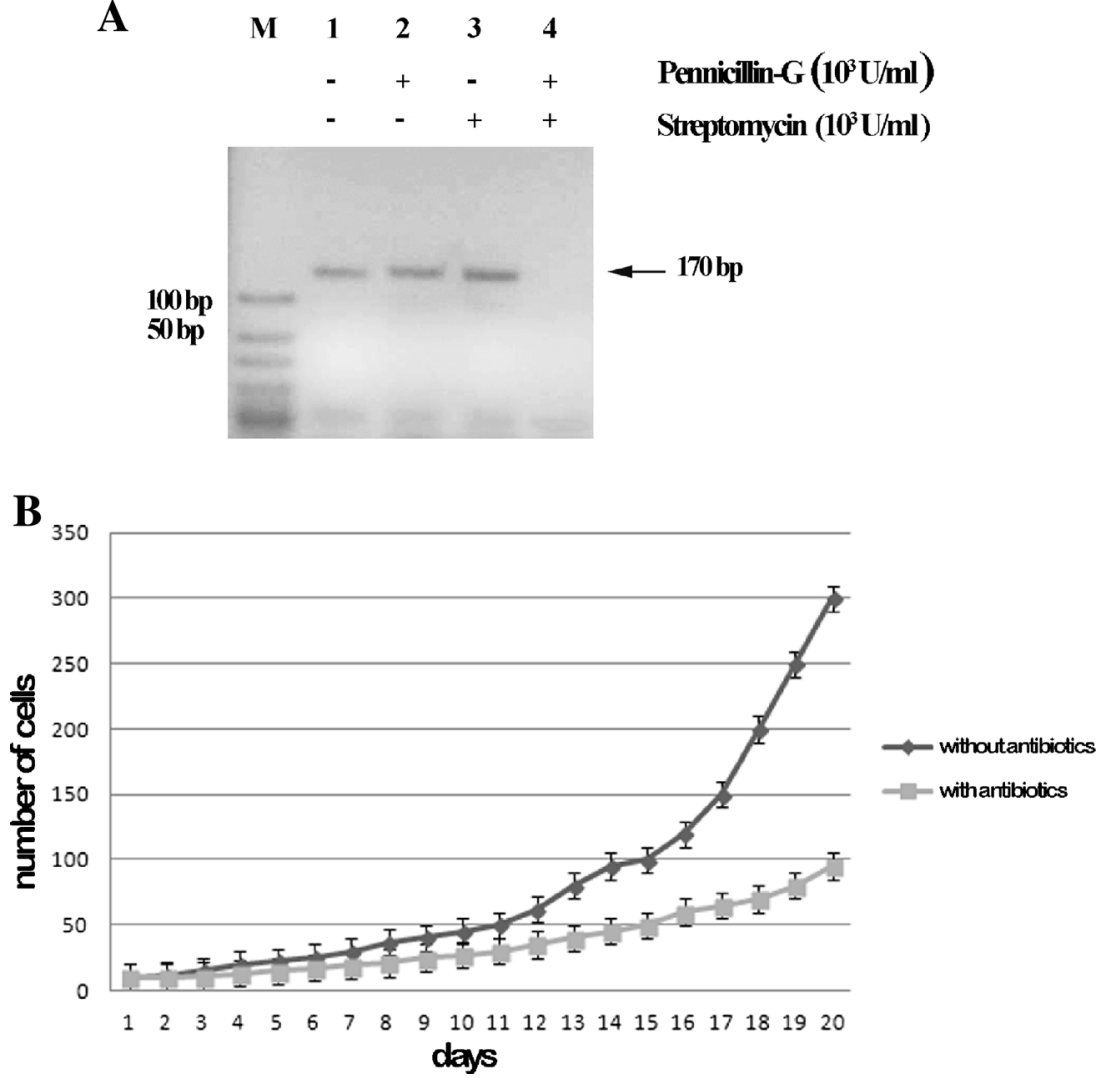

derived from a temperate environment [6]. To our best knowledge, this is the first report of the characterization of Francisella sequences associated to an organism derived from Antarctic environment. Our results can contribute to uncover new environmental reservoirs of old diseases.

Most of the Alphaproteobacteria sequences of the consortium belong to the order Rhodobacterales. Marine Rhodobacterales are a widespread, abundant, and metabolically versatile bacterial group in the world's oceans. They also show a nearly universal conservation of the genes for production of GTAs, virus-like particles that mediate genetic exchange between cells [67]. A GTA encoding gene is present in the $E$. focardii bacterial consortium, as well as members of the transposase and integrase superfamilies. The significance of horizontal gene transfer in bacterial evolution and creation of "novel" catabolic pathways for bacterial adaptation is now well established. Fully sequenced genomes revealed that a substantial fraction of ORFs have been horizontally transferred [68, 69], and many of these acquisitions are thought to have driven adaptation to new ecological niches [70].

Transposable genetic elements (TEs) and transposition may play a profoundly generative role in genome evolution [71] and in the responsive capacity of organisms in the face of environmental challenges. TEs are likely to play a relevant role in adaptation because of their ability to generate mutations of great variety and magnitude, and their capacity to be responsive and susceptible to environmental changes [72-75].
Although our study has been performed on a long lasting E. focardii laboratory strain, the obtained results strongly suggest that the bacterial consortium presently associated to the ciliate culture largely reflects the original psychrophilic one from the Antarctic environment. Our analysis suggests unique cold adaptation characteristics of the consortium such as the abilities to synthesize and breakdown high molecular weight compounds, as well as carbon metabolism, important in carbon and nutrient cycling in the cold marine environment [48]. Therefore, it appears that the ecological role of the consortium includes catabolism of complex substances for carbon and energy reserves that insures survival when cold environmental conditions may set limitations on uptake of such carbon and nitrogen reserves from other sources [41]. Bacterial intracellular carbon and nitrogen reserves most probably contribute to nutrient provision also to $E$. focardii. In other words, the presence of this consortium associated to E. focardii cells may have aided this ciliate to adapt and survive under the highly selective cold conditions of the Antarctic habitat.

Previous papers reported that some Euplotes species cannot divide properly and eventually die when the endosymbiontic bacteria are removed by antibiotic treatment [76, 77]. Our analysis shows that antibiotic treated $E$. focardii cells are still able to divide even though antibiotic treatments reduce cell proliferation. This result suggests that the bacterial consortium, beside not essential, is probably helpful to the ciliate in the specific 
laboratory growing condition and might be useful to the ciliate also in the natural Antarctic environment. This hypothesis is supported not only by the identification of enzymes responsible for carbon and nitrogen storage, but also by the result obtained from the GO annotation in which most of the terms include proteins involved in oxidoreductase activity. It is well known that one of the major problems of marine cold-adapted organisms is to cope with increased $\mathrm{O}_{2}$ solubility at low temperatures that determines an increased level of reactive oxygen species (ROS) in their cells. Therefore, increased defenses against oxidative stress most likely constituted an important aspect of evolutionary adaptation of these organisms in their oxygen-rich environment.

An additional contribution of the bacterial consortium to cold-adaptation most likely derives from the synthesis of antifreeze proteins. Among the bacterial sequences, we identified contigs that encode proteins highly similar to the antifreeze proteins identified in other organisms, including $S$. aurantiaca strain DW4/3-1, which was isolated from the glacier of the Antarctic Lower Victoria valley and Flavobacteriaceae bacterium strain 3519-10, which was isolated from the glacial ice of the Lake Vostok [54]. Furthermore, by using AFP-Pred and iAFP bioinformatic tools, we predicted 2755 (using AFPPred) and 600 (using iAFP) contigs that potentially encode AFPs in Gammaproteobacteria, 2251 (by AFP-Pred) and 500 (by iAFP) in Alphaproteobacteria, and 942 (by AFP-Pred) and 200 (by iAFP) in Betaproteobacteria. These sequences may represent new AFPs which activity must be verified but potentially may contribute to the survival of both bacteria and E. focardii cells in the cold.

To conclude, our results support the concept that bacterial consortia associated to other living organisms represent major players in the ecology of species adaptation.

Acknowledgments This work was supported by grants from the Italian "Programma Nazionale di Ricerche in Antartide" (PNRA) to CM and SP and from the Italian "Ministero dell'Istruzione, dell' Università e della Ricerca" (MIUR), the European Commission FP7-PEOPLE-2009IRSES project CINAR PATHOBACTER (247658) to GP, and the Volkswagen foundation (project number: 84816) to MS. We acknowledge the COST (action BM1102) for supporting part of this work. The authors wish to thank S. Gabrielli for technical assistance in graphic artwork.

Open Access This article is distributed under the terms of the Creative Commons Attribution License which permits any use, distribution, and reproduction in any medium, provided the original author(s) and the source are credited.

\section{References}

1. Clark MS, Clarke A, Cockell CS, Convey P, Detrich HW 3rd, Fraser KP, Johnston IA, Methe BA, Murray AE, Peck LS, Römisch K,
Rogers AD (2004) Antarctic genomics. Comput Funct Genomics 5(3):230-238

2. Petz W (2005) Ciliates. In: Scott FJ, Marchant HJ (eds) Antarctic marine protists. Australian Biological Resources Study, Canberra, pp 347-448

3. Finlay BJ, Corliss JO, Esteban G, Fenchel T (1996) Biodiversity at the microbial level: the number of free-living ciliates in the biosphere. Q Rev Biol 3:221-237

4. Orsi W, Charvet S, Vd'ačný P, Bernhard JM, Edgcomb VP (2012) Prevalence of partnerships between bacteria and ciliates in oxygendepleted marine water columns. Front Microbiol 19(3):341

5. Anderson OR (2014) Living together in the plankton: a survey of marine protist symbioses. Acta Protozool 53(199):29-38

6. Schrallhammer M, Schweikert M, Vallesi A, Verni F, Petroni G (2011) Detection of a novel subspecies of Francisella noatunensis as endosymbiont of the ciliate Euplotes raikovi. Microb Ecol 61(2): 455-464. doi:10.1007/s00248-010-9772-9

7. Fenchel T, Finlay BJ (1991) The biology of free-living anaerobic ciliates. Eur J Protistol 22;26(3-4):201-215. doi: 10.1016/S09324739(11)80143-4

8. Fenchel T, Bernard C (1993) Endosymbiotic purple non sulphur bacteria in an anaerobic ciliated protozoon. FEMS Microbiol Lett 110: $21-25$

9. Petroni G, Spring S, Schleifer KH, Verni F, Rosati G (2000) Defensive extrusive ectosymbionts of Euplotidium (Ciliophora) that contain microtubule-like structures are bacteria related to Verrucomicrobia. Proc Natl Acad Sci U S A 97(4):1813-1817

10. Schrallhammer M, Schweikert M (2009) The Killer Effect of Paramecium and Its Causative Agents in: Endosymbionts in Paramecium, Microbiology Monographs, Fujishima M (ed), Springer Berlin Heidelberg pp. 227-246

11. Robles Alonso V, Guarner F (2013) Linking the gut microbiota to human health. Br J Nutr 109(Suppl 2):S21-6

12. Woyke T, Teeling H, Ivanova NN, Hunteman M, Richter M, Gloeckner FO et al.(2006). Symbiosis insights through metagenomic analysis of a microbial consortium. Lawrence Berkeley National Laboratory: Lawrence Berkeley National Laboratory. Retrieved from: http://escholarship.org/uc/item/0mx2050n

13. Ashton M, Rosado W, Govind NS, Tosteson TR (2003) Culturable and nonculturable bacterial symbionts in the toxic benthic dinoflagellate. Ostreopsis Lenticularis Toxicon 42(4):419-424

14. Pérez-Guzmán L, Pérez-Matos AE, Rosado W, Tosteson TR, Govind NS (2008) Bacteria associated with toxic clonal cultures of the dinoflagellate Ostreopsis lenticularis. Mar Biotechnol 10(5):492-6

15. Valbonesi A, Luporini P (1993) Biology of Euplotes focardii an Antarctic ciliate. Polar Biol 13:489-493

16. Pucciarelli S, la Terza A, Ballarini P, Barchetta S, Yu T, Marziale F, Passini V, Methé B, Detrich HW 3rd, Miceli C (2009) Molecular cold-adaptation of protein function and gene regulation: the case for comparative genomic analyses in marine ciliated protozoa. Mar Genomics 2(1):57-66

17. la Terza A, Papa G, Miceli C, Luporini P (2001) Divergence between two Antarctic species of the ciliate Euplotes, E. focardii and E. nobilii, in the expression of heat-shock protein 70 genes. Mol Ecol 10(4):1061-7

18. Yang G, Yang G, Aprile L, Turturo V, Pucciarelli S, Pucciarelli S, Miceli C (2013) Characterization and comparative analysis of psychrophilic and mesophilic alpha-amylases from Euplotes species: a contribution to the understanding of enzyme thermal adaptation. Biochem Biophys Res Commun 438(4):715-20

19. Yang G, de Santi C, de Pascale D, Pucciarelli S, Pucciarelli S, Miceli C (2013) Characterization of the first eukaryotic cold-adapted patatin-like phospholipase from the psychrophilic Euplotes focardii: identification of putative determinants of thermal-adaptation by comparison with the homologous protein from the mesophilic Euplotes crassus. Biochimie 95(9):1795-806 
20. Pucciarelli S, Chiappori F, Sparvoli D, Milanesi L, Miceli C, Melki R (2013) Tubulin folding: the special case of a beta-tubulin isotype from the Antarctic psychrophilic ciliate Euplotes focardii. Polar Biol 36(12):1833-1838

21. Chiappori F, Pucciarelli S, Merelli I, Ballarini P, Miceli C, Milanesi L (2012) Structural thermal adaptation of $\beta$-tubulins from the Antarctic psychrophilic protozoan Euplotes focardii. Proteins 80(4):1154-66

22. Marziale F, Pucciarelli S, Ballarini P, Melki R, Uzun A, Ilyin VA, Detrich HW 3rd, Miceli C (2008) Different roles of two gammatubulin isotypes in the cytoskeleton of the Antarctic ciliate Euplotes focardii: remodelling of interaction surfaces may enhance microtubule nucleation at low temperature. FEBS J 275(21):5367-82

23. Pucciarelli S, Marziale F, di Giuseppe G, Barchetta S, Miceli C (2005) Ribosomal cold-adaptation: characterization of the genes encoding the acidic ribosomal $\mathrm{P} 0$ and $\mathrm{P} 2$ proteins from the Antarctic ciliate Euplotes focardii. Gene 360(2):103-10

24. Pucciarelli S, Miceli C (2002) Characterization of the cold-adapted alpha-tubulin from the psychrophilic ciliate Euplotes focardii. Extremophiles 6(5):385-389

25. Miceli C, la Terza A, Melli M (1989) Isolation and structural characterization of cDNA clones encoding the mating pheromone Er-1 secreted by the ciliate Euplotes raikovi. Proc Natl Acad Sci U S A 86(9):3016-3020

26. Huson DH, Auch AF, Qi J, Schuster SC (2007) MEGAN analysis of metagenomic data. Genome Res 17(3):377-86

27. Sun S, Chen J, Li W, Altintas I, Lin A, Peltier S, Stocks K, Allen EE, Ellisman M, Grethe J, Wooley J (2011) Community cyberinfrastructure for Advanced Microbial Ecology Research and Analysis: the CAMERA resource. Nucleic Acids Res. D546-51. doi: 10.1093/nar/gkq1102

28. Punta M, Coggill PC, Eberhardt RY, Mistry J, Tate J, Boursnell C, Pang N, Forslund K, Ceric G, Clements J, Heger A, Holm L, Sonnhammer ELL, Eddy SR, Bateman A, Finn RD (2012) The Pfam protein families database. Nucleic Acids Res 40:290-301

29. Haft DH, Selengut JD, White O, The TIGRFAMs database of protein families (2003) Nucleic Acids Res 31(1):371-373

30. Tatusov RL, Galperin MY, Natale DA, Koonin EV (2003) The COG database: a tool for genome-scale analysis of protein functions and evolution. Nucleic Acids Res 28(1):33-36

31. Li W (2009) Analysis and comparison of very large metagenomes with fast clustering and functional annotation. BMC Bioinforma 10: 359. doi:10.1186/1471-2105-10-359

32. Lingner T, Asshauer KP, Schreiber F, Meinicke P. (2011) CoMet-a web server for comparative functional profiling of metagenomes. Nucleic Acids Res. 39 (Web Server issue):W518-23. doi: 10.1093/ nar/gkr388.

33. Pruesse E, Quast C, Knittel K, Fuchs BM, Ludwig W, Peplies J, Glöckner FO (2007) SILVA: a comprehensive online resource for quality checked and aligned ribosomal RNA sequence data compatible with ARB. Nucleic Acids Res 35:7188-7196. doi:10.1093/nar/ gkm864

34. Ludwig W, Strunk O, Westram R, Richter L, Meier H et al (2004) ARB: a software environment for sequence data. Nucleic Acids Res 32:1363-1371. doi:10.1093/nar/gkh293

35. Guindon S, Gascuel O (2003) A simple, fast, and accurate algorithm to estimate large phylogenies by maximum likelihood. Syst Biol 52: 696-704

36. Darriba D, Taboada GL, Doallo R, Posada D (2012) jModelTest 2: more models, new heuristics and parallel computing. Nat Methods 9(8):772

37. Kandaswamy KK, Chou KC, Martinetz T, Moller S, Suganthan PN, Sridharan S, Pugalenthi G (2011) AFP-Pred: a random forest approach for predicting antifreeze proteins from sequence-derived properties. J Theor Biol 270(1):56-62. doi:10.1016/j.jtbi.2010.10. 037
38. Yu CS, Lu CH (2011) Identification of antifreeze proteins and their functional residues by support vector machine and genetic algorithms based on n-peptide compositions. PLoS One 6(5):e20445. doi:10. 1371/journal.pone.0020445

39. Choudhari S, Smith S, Owens S, Gilbert JA, Shain DH, Dial RJ, Grigoriev A (2013) Metagenome sequencing of prokaryotic microbiota collected from Byron Glacier, Alaska. Genome Announc 21;1(2):e0009913. doi: 10.1128/genomeA.00099-13

40. Gosink JJ, Woese CR, Staley JT (1998) Polaribacter gen. nov., with three new species, $P$. irgensii sp. nov., $P$. franzmannii sp. nov., and $P$. filamentus sp. nov., gas vacuolate polar marine bacteria of the Cytophaga-Flavobacterium-Bacteroides group and reclassification of 'Flectobacillus glomeratus' as Polaribacter glomeratus comb. nov. Int J Syst Bacteriol 48(1):223-235

41. Methé BA, Nelson KE, Deming JW, Momen B, Melamud E, Zhang $\mathrm{X}$ et al (2005) The psychrophilic lifestyle as revealed by the genome sequence of Colwellia psychrerythraea 34H through genomic and proteomic analyses. Proc Natl Acad Sci U S A 102(31):10913-8

42. Uchino Y, Hirata A, Yokota A, Sugiyama J (1998) Reclassification of marine Agrobacterium species: proposals of Stappia stellulata gen. nov., comb. nov., Stappia aggregata sp. nov., nom. rev., Ruegeria atlantica gen. nov., comb. nov., Ruegeria gelatinovora comb, nov., Ruegeria algicola comb. nov., and Ahrensia kieliense gen. nov., sp. nov., nom. rev. J Gen Appl Microbiol 44(3):201-210

43. Gutierrez T, Nichols PD, Whitman WB, Aitken MD (2012) Porticoccus hydrocarbonoclasticus sp. nov., an aromatic hydrocarbon-degrading bacterium identified in laboratory cultures of marine phytoplankton. Appl Environ Microbiol 78(3):628-37

44. Ivanova EP, Nedashkovskaya OI, Chun J, Lysenko AM, Frolova GM, Svetashev VI, Vysotskii MV, Mikhailov VV, Huq A, Colwell RR (2001) Arenibacter gen. nov., new genus of the family Flavobacteriaceae and description of a new species, Arenibacter latericius sp nov. Int J Syst Evol Microbiol 51(6):1987-1995

45. Vannini C, Rosati G, Verni F, Petroni G (2004) Identification of the bacterial endosymbionts of the marine ciliate Euplotes magnicirratus (Ciliophora, Hypotrichia) and proposal of 'Candidatus Devosia euplotis'. Int J Syst Evol Microbiol 54(Pt 4):1151-1156

46. Kalyuzhnaya MG, Bowerman S, Lara JC, Lidstrom ME, Chistoserdova L (2006) Methylotenera mobilis gen. nov., sp. nov., an obligately methelamine-utilizing bacterium within the family Methylophilaceae. Int J Syst Evol Microbiol 56(12):2819-2823

47. Vollmers J, Voget S, Dietrich S, Gollnow K, Smits M, Meyer K, Brinkhoff T, Simon M, Daniel R (2013) Poles apart: arctic and antarctic octadecabacter strains share high genome plasticity and a new type of xanthorhodopsin. PLoS One 8(5):e63422. doi:10.1371/ journal.pone.0063422

48. Zhou MY, Wang GL, Li D, Zhao DL, Qin QL, Chen XL, Chen B, Zhou BC, Zhang XY, Zhang YZ (2013) Diversity of both the cultivable protease-producing bacteria and bacterial extracellular proteases in the coastal sediments of King George Island, Antarctica. PLoS One 8(11):e79668. doi:10.1371/journal.pone.0079668

49. Martin DD, Bartlett DH, Roberts MF (2002) Solute accumulation in the deep-sea bacterium Photobacterium profundum. Extremophiles 6(6):507-14

50. Heiss G, Trachtmann N, Abe Y, Takeo M, Knackmuss HJ (2003) Homologous npdGI genes in 2,4-dinitrophenol- and 4-nitrophenoldegrading Rhodococcus spp. Appl Environ Microbiol 69(5):27482754

51. Deppenmeier U, Blaut M, Mahlmann A, Gottschalk G (1990) Reduced coenzyme F420: heterodisulfide oxidoreductase, a protontranslocating redox system in methanogenic bacteria. Proc Natl Acad Sci U S A 87(23):9449-9453

52. Huntley S, Hamann N, Wegener-Feldbrügge S, Treuner-Lange A, Kube M, Reinhardt R, Klages S, Müller R, Ronning CM, Nierman WC, Søgaard-Andersen L (2011) Comparative genomic analysis of fruiting body formation in Myxococcales. Mol Biol Evol 28(2):1083-97 
53. Raymond JA, Christner BC, Schuster SC (2008) A bacterial icebinding protein from the Vostok ice core. Extremophiles 12(5): 713-717

54. Pucciarelli S, Devaraj RR, Ballarini P, Yu T, Yang G, Miceli C (2014) Identification and analysis of two sequences encoding ice-binding proteins obtained from a putative bacterial symbiont of the psychrophilic Antarctic ciliate Euplotes focardii. Antarct Sci 2:1-11

55. Kang I, Vergin KL, Oh HM, Choi A, Giovannoni SJ, Cho JC (2011) Genome sequence of strain HTCC2083, a novel member of the marine clade Roseobacter. J Bacteriol 193(1):319-20

56. Wang CM, Lo LC, Feng F, Gong P, Li J, Zhu ZY, Lin G, Yue GH (2008) Construction of a BAC library and mapping BAC clones to the linkage map of Barramundi, Lates calcarifer. BMC Genomics 25(9):139

57. Lang AS, Zhaxybayeva O, Beatty JT (2012) Gene transfer agents: phage-like elements of genetic exchange. Nat Rev Microbiol 10(7): 472-82. doi:10.1038/nrmicro2802, Review

58. Hagemann S, Stöger L, Kappelmann M, Hass1 I, Ellinger A, Velimirov B (2013) DNA-bearing membrane vesicles produced by Ahrensia kielensis and Pseudoalteromonas marina. J Basic Microbiol. doi:10.1002/jobm.201300376

59. Duodu S, Larsson P, Sjödin A, Forsman M, Colquhoun DJ (2012) The distribution of Francisella-like bacteria associated with coastal waters in Norway. Microb Ecol 64(2):370-7. doi:10.1007/s00248012-0023-0, PMID: 22370877

60. Nalbantoglu U, Sayood K, Dempsey MP, Iwen PC, Francesconi SC, Barabote RD, Xie G, Brettin TS, Hinrichs SH, Fey PD (2010) Large direct repeats flank genomic rearrangements between a new clinical isolate of Francisella tularensis subsp. tularensis A1 and Schu S4. PLoS One 5(2):e9007. doi:10.1371/journal.pone.0009007

61. Gong J, Qing Y, Guo X, Warren A (2014) “Candidatus Sonnebornia yantaiensis", a member of candidate division OD1, as intracellular bacteria of the ciliated protist Paramecium bursaria (Ciliophora, Oligohymenophorea). Syst Appl Microbiol 37(1):35-41

62. Boscaro V, Schrallhammer M, Benken KA, Krenek S, Szokoli F, Berendonk TU, Schweikert M, Verni F, Sabaneyeva EV, Petroni G (2013) Rediscovering the genus Lyticum, multiflagellated symbionts of the order Rickettsiales. Sci Rep 3:3305. doi:10.1038/srep03305

63. Schrallhammer M, Ferrantini F, Vannini C, Galati S, Schweikert M, Görtz HD, Verni F, Petroni G (2013) 'Candidatus Megaira polyxenophila' gen. nov., sp. nov.: considerations on evolutionary history, host range and shift of early divergent rickettsiae. PLoS ONE 8:e72581. doi:10.1371/journal.pone.0072581
64. Fokin SI (2012) Frequency and biodiversity of symbionts in representatives of the main classes of Ciliophora. Eur J Protistol 48:138-148

65. Abd H, Johansson T, Golovliov I, Sandstrom G, Forsman M (2003) Survival and growth of Francisella tularensis in Acanthamoeba castellanii. Appl Environ Microbiol 69:600-606

66. Thelaus J, Andersson A, Mathisen P, Forslund AL, Noppa L, Forsman M (2009) Influence of nutrient status and grazing pressure on the fate of Francisella tularensis in lakewater. FEMS Microbiol Ecol 67:69-80

67. Fu Y, Keats KF, Rivkin RB, Lang AS (2013) Water mass and depth determine the distribution and diversity of Rhodobacterales in an Arctic marine system. FEMS Microbiol Ecol 84(3):564-76. doi:10. 1111/1574-6941.12085

68. Nakamura Y, Itoh T, Matsuda H, Gojobori T (2004) Biased biological functions of horizontally transferred genes in prokaryotic genomes. Nat Genet 36(7):760-6

69. McDaniel LD, Young E, Delaney J, Ruhnau F, Ritchie KB, Paul JH (2010) High frequency of horizontal gene transfer in the oceans. Science 330(6000):50. doi:10.1126/science.1192243

70. Wiedenbeck J, Cohan FM (2011) Origins of bacterial diversity through horizontal genetic transfer and adaptation to new ecological niches. FEMS Microbiol Rev 35(5):957-76. doi:10.1111/j.15746976.2011.00292.x

71. Fedoroff NV (2012) Presidential address. Transposable elements, epigenetics, and genome evolution. Science 338(6108):758-767

72. Biémont C, Vieira C (2006) Genetics: junk DNA as an evolutionary force. Nature 5;443(7111):521-524

73. Schmidt AL, Anderson LM (2006) Repetitive DNA elements as mediators of genomic change in response to environmental cues. Biol Rev Camb Philos Soc 81(4):531-43

74. Oliver KR, Greene WK (2012) Transposable elements and viruses as factors in adaptation and evolution: an expansion and strengthening of the TE-Thrust hypothesis. Ecol Evol 2(11):2912-33. doi:10.1002/ ece 3.400

75. Hua-Van A, le Rouzic A, Boutin TS, Filée J, Capy P (2011) The struggle for life of the genome's selfish architects. Biol Direct 17(6):19. doi:10.1186/1745-6150-6-19, Review

76. Heckmann K, ten Hagen R, Görtz HD (1983) Freshwater Euplotes species with 9 type I cirrus pattern depend upon endosymbionts. J Protozool 30:284-289

77. Vannini C, Petroni G, Verni F, Rosati G (2005) Polynucleobacter bacteria in the brackish-water species Euplotes harpa (Ciliata, Hypotrichia). J Eukariot Microbiol 52:116-122 